\title{
OS ESTUDOS DA TRADUÇÃO NA ROMÊNIA E SUAS RELAÇÕES SINCRÔNICAS E TARDIAS COM OS ESTUDOS DA TRADUÇÃO NA EUROPA: ALGUMAS LINHAS DE PESQUISA
}

\author{
TRANSLATION STUDIES IN ROMANIA. THEIR SYNCHRONIC AND DEFERRED \\ RELATIONS WITH EUROPEAN TRANSLATION STUDIES. A FEW DIRECTIONS \\ OF RESEARCH
}

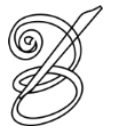 \\ Georgiana LUNGU-BADEA* \\ Universidade do Oeste de Timişoara \\ Timişoara, Timiş, Romania \\ Universidade de Brasília \\ Brasília, Distrito Federal, Brasil \\ Traduzido por*: \\ Ana Alethea de Melo Cesar OSÓRIO*** \\ Universidade de Brasília \\ Brasília, Distrito Federal, Brasil
}

Resumo $^{1}$ : Este artigo tem como foco explorar alguns aspectos relacionados aos estudos da tradução contemporâneos na Romênia, além de identificar influências, convergências e divergências entre as várias linhas de pesquisa presentes na Europa Ocidental, Central e Oriental, e os estudos da tradução na Romênia. A tentativa de oferecer uma tipologia dos trabalhos de estudos da tradução existentes dentro e fora do espaço em questão é acompanhada pelo exame de fatores que levam à escolha de línguas não nativas para a publicação de tais trabalhos. Palavras-chave: Tradução. Teoria da Tradução. Estudos da Tradução. Prática da Tradução. Didática da Tradução. História da Tradução.

Abstract: This article sets out to explore a few aspects related to present-day translation studies in Romania, as well as to identify influences, convergences and divergences among various research directions present within the Western, Central and Eastern European, and Romanian translation studies. The attempt to offer a typology of works of translation studies existing within and outside the space focused on is accompanied by the examination of factors that lead to the choice of non-native languages for the publication of such works.

Key words: Translation. Theory of Translation. Translation Studies. Practice of Translation. Didactics of Translation. History of Translation.

RECEBIDO EM: 10 de novembro de 2019

ACEITO EM: 30 de novembro de 2019

PUBLICADO EM: abril 2020 


\section{OS ESTUDOS DA TRADUÇÃO NA ROMÊNIA E SUAS RELAÇÕES SINCRÔNICAS E TARDIAS COM OS ESTUDOS DA TRADUÇÃO NA EUROPA: ALGUMAS LINHAS DE PESQUISA}

\section{Introdução}

Para analisar os estudos da tradução na Romênia e suas relações sincrônicas e tardias com seus homólogos ocidentais, não é apenas útil, mas também necessário, relacioná-los aos modelos ocidentais, europeus ou não, tanto na análise do romeno (e, parcialmente, do espaço da Europa Central) ${ }^{2}$ quanto na apresentação sintética das principais tendências nos estudos da tradução. Com seus vários nomes (inglês: translation studies, translatology, ${ }^{3}$ francês: traductologie, ${ }^{4}$ alemão: Übersetzungswissenschaft, ${ }^{5}$ Translationswissenchaft ${ }^{6}$ ) e com as fronteiras de suas áreas de pesquisa constantemente se ajustando tanto à teoria quanto à prática/arte/ciência da tradução, os estudos da tradução primeiro conheceram a atomização para em seguida passar pela globalização.

Apesar de se relacionarem com outros pontos nodais além dos estudos da tradução

104 ocidentais (apesar de dessincronizados), é importante mapear os estudos da tradução da Europa Central e Oriental tanto para refletir acerca do estado atual da pesquisa dentro da área quanto para poder, por um lado, estabelecer a filiação de ideias, sua genealogia, a influência exercida pela mídia ocidental e, por outro, identificar a predisposição e/ou necessidade de seguir certos modelos em detrimento de outros, além dos fatores que afetam essas decisões. As dificuldades inerentes à realização de um estudo estatístico, relativas principalmente à natureza das línguas nacionais, têm gerado uma perspectiva fragmentada sobre o fenômeno, sobre a história e a historiografia recente dos estudos da tradução, limitando-se às obras publicadas em línguas de grande circulação ou traduzidas a partir destas.

Essas são as razões pelas quais decidimos limitar o nosso estudo aos estudos da tradução romenos e apenas fazer referência aos estudos da tradução internacionais, tentando estabelecer o seu denominador comum e os elementos distintivos daqueles. Portanto, este artigo apenas abre a porta para nossa pesquisa, que se propõe a estabelecer os aspectos definidores, variáveis e invariáveis, dos estudos da tradução.

Assim como na Alemanha, por exemplo, seguindo a análise sistemática conduzida por Wills nos anos 1970, vimos uma orientação tripartite, ${ }^{7}$ com várias subdivisões na Romênia - e, guardadas as devidas proporções, na Europa Central. Há um interesse constante e crescente na teoria e na prática da tradução, nos seus estudos e padrões críticos, na sua história e didática, 
características que devem justificar o seu caráter aparentemente menos inovador (como a pesquisa em tradução conduzida por A. V. Fedorov em 1953), se compararmos com os estudos da tradução ocidentais (iniciais, por exemplo, Vinay e Darbelnet em 1958, menos preocupados em compreender a experiência passada e mais preocupados com a prática).

As várias abordagens às questões da tradução destacam vários aspectos e soluções originais, de modo que as teorias apresentadas não se aniquilem, mas se complementem mutuamente e esbocem uma imagem geral do fenômeno da tradução. Essa diversidade foi provocada, desde os anos 1970, por uma variedade de objetivos institucionais, pela supremacia do interesse nacional, pela tradição e pelas considerações extralinguísticas e políticas dominantes (a teoria dos polissistemas em Israel, a teoria finlandesa e alemã da psicolinguística, etc.) e assim por diante. Bastante descritivas no início, as teorias da tradução integram pesquisas de áreas adjacentes (linguística, psicologia, psicolinguística, sociologia, etnologia, etc.), e as análises subsequentes integram a textologia, as teorias funcionais, a estética da recepção, a pragmática, etc.

\section{[A] Influências e linhas de pesquisa dos estudos da tradução ocidentais}

As contribuições à pesquisa em estudos da tradução, seja ela fundamental ou aplicada, inovadora, inter e transdisciplinar, podem ser agrupadas de acordo com vários critérios (tipos de teorias, ângulos de análise, intenções específicas). Os estudos da tradução, quer teóricos e experimentais, quer aplicados, apresentam várias características, e muitas vezes não podemos falar sobre isso em termos estritos: 1) descritivos e analíticos (que se referem ao texto-alvo como resultado do processo de tradução e do contexto da tradução);

2) prescritivos e que definem normas, com foco no processo e nas regras que devem ser observadas pelo tradutor; 3) prospectivos, com foco no propósito da tradução em relação ao texto-alvo ou ao destinatário. Devido a tal multiplicidade de escopos, pode-se estabelecer várias relações, tais como: linguística e tradução (JAKOBSON, 1959; MOUNIN, 1963; NIDA, 1964; CATFORD, 1965; CHARAUDEAU, 1972; PERGNIER, 1972); tradução como resultado e processo (BELL, 1991; NEWMARK; GUTT, 1991; TOROP, 1995); tradução e línguas em contraste/em um relação comparativa (MALBLANC, 1944; VINAY; DARBELNET, 1958; CARY, 1959; GUILLEMIN-FLESCHER, 1981); tradução e literatura (Jiří LEVÝ, Literary Translation as an Art Form, ([1963]/2006); O. PAZ, 1971; A. LEFEVERE, 1977); padronização da tradução, tendências de padronização, técnicas e estratégias de tradução, crítica de tradução, didática da tradução (MOUNIN, 1955; REISS, 
1971; NEWMARK, 1981, 1987; DELISLE, 1980, 1993, 1998; REISS; VERMEER, 1984; BERMAN, 1995); tradução, hermenêutica, filosofia da linguagem e teorias literárias (WANDRUSZKA, 1969, 1979; MESCHONNIC, 1973; STEINER, 1975; ETKIND, 1982; BERMAN, 1984); tradução e transferência cultural, diferenças culturais e intraduzibilidade (PERGNIER, 1978; MARGOT, 1979; OKSAAR, 1988; VERMEER; WITTE, 1990; BASNETT; LEFEVERE, 1990; CORDONNIER, 1990; CHESTERMAN, 1997; HATIM, 1997; CASSIN, 2004); história da tradução (MOUNIN, 1965; VAN HOOF, 1991; BALLARD, 1992, 2013; DELISLE, 1995, 1999, 2002; VENUTI, 1995; PYM, 1998; BAKER, 1998; DELISLE; LAFOND, 1999); teoria da tradução, teorias contemporâneas da tradução (FEDOROV, 1953, 1968; HOLMES, 1972; TOURY, 1980; HOLZ-MÄNTTARI, 1984, 1990; LAROSE, 1989; NORD, 1993; ROBINSON, 1997; HICKEY, 1998; OSEKIDÉPRÉ, 1998; GENTZLER, 2001; PYM, 2008); sociologia, crítica social e sociolinguística da tradução (BRISSET, 1990; GOUANVIC, 1999; HEILBRON; SAPIRO 1999; PETEERS, 1999; AKCRIH; CALLON; LATOUR, 2006).

Para além das várias ligações aqui mencionadas, as questões de tradução também podem

- [I] a dicotomia literário $\mathrm{X}$ não literário, que investiga, por exemplo: 1) a tradução de textos literários (contemporânea do próprio texto literário ou em outra época que não a da publicação do texto, quando o tradutor deve levar em consideração a evolução interna do texto-fonte e a evolução externa do idioma de destino, bem como o gosto do público receptor);

2) questões relacionadas a textos não literários ou técnico-científicos;

- [II] fragmentariedade dependendo dos vários níveis de percepção, como: 1) a tradução de textos didáticos (aprendizado de língua estrangeira) $X$ 2) tradução de textos publicitários;

1) e 2) X 3) tradução de textos especializados e assim por diante.

Embora seja óbvio, mesmo sem uma análise dos títulos, que o nome teoria esteja muito bem representado, não vamos insistir nas teorias, mas na pesquisa em estudos da tradução, pois aborda a relação entre estudos da tradução e linguística, antropologia, teoria da comunicação, sociologia, psicologia e história, ciências econômicas, teoria da literatura, etc., e estudos sobre 
tradução automática e assistida por computador com base nas ciências exatas (matemática, ciência da computação, cibernética).

O tempo em que disciplinas distintas como a linguística e a teoria da literatura, a teoria da cultura, a sociolinguística, etc., reivindicavam as teorias da tradução como suas já passou; no entanto, ainda podemos debater sobre o peso de tais disciplinas, se esse peso é considerável (MIKO, 1970, p. 61) e se elas podem dificultar a pesquisa, por meio de uma orientação perniciosa.

A pesquisa em estudos da tradução é, no entanto, caracterizada por uma emulação simultânea. Escreveu-se sobre os princípios e regras da tradução muito antes do século XX e o estabelecimento dos estudos da tradução como uma disciplina. Cícero, Horácio, Quintiliano, Jerônimo, Agostinho, Lutero, Dolet, Dryden, Da Longiano, Antoine Lemaître de Sacy, Chaucer, Tytler, Newman, Matthew, Goethe, Bodmer e Breitinger são somente alguns dos que abordaram o assunto. Nessa tradição normativo-descritiva, e também programática, que busca designar o que deveria necessariamente ser traduzido por uma cultura, podemos listar a obra do começo do século XX Principles of Literary Translation, ${ }^{8}$ de Ciukovski e Gumilov (1919), que precede "A tarefa do tradutor" de Walter Benjamin (1921), seguida dez anos depois por Theory and Practice of Translation de Finkel (1928). No entanto, os estudos da tradução europeus são definidos por uma espécie de sincronia de que os estudiosos não têm conhecimento e da qual, no início, não tinham necessidade, pois não parecem ter por objetivo generalizar o processo de tradução, mas sim particularizá-lo a favor da sua língua materna. Trata-se, obviamente, de um tipo de estudos da tradução intralíngue. Não se trata de um regresso à atitude pré-século XVI, mas a tradução é percebida como um componente identitário da cultura nacional, realizando-se ao servir às "necessidades" do contexto-alvo; a abordagem instrumental (como é feita, por meio de quais técnicas e instrumentos) parece ceder à abordagem objetiva (para que finalidade, para que público?).

Entre os primeiros teóricos da tradução - juntamente com E. A. Nida e os Principles of Translation as Exemplified by Bible Translating, Andrei Fedorov (1953) e sua famosa obra Introduction to the Theory of Translation, (reeditada continuamente em russo e em publicação em romeno), a Stylistique comparée du français et de l'anglais de Vinay e Darbelnet (1958), publicações institucionais internacionais, como Scientific and technical translating and other aspects of the language problem da Unesco (1958) -, próximos a todos eles, às vezes os precedendo, estão pesquisadores cujos nomes e obras são pouco conhecidos fora desses territórios linguísticos. Os títulos de suas obras mostram seu interesse em teorizar a tradução: 
- 1957: Wojtasiewicz publica uma introdução à teoria da tradução;

- 1962: Larin aborda a teoria e a crítica de tradução;

- 1963: o teórico tcheco Jiř́ Levý publica Umení prekladu (The art of translation); o iugoslavo Simić, uma antologia de textos de tradução;

- 1964: Rozencvejg aborda tradução, transformações interlinguais e estruturas linguísticas;

- 1966: Horalek estuda os princípios da tradução;

- 1967: A. Ljudskanov, Preveždat čovekăt i mašinata, Nauka i izkustvo (publicada em francês Traduction humaine et traduction mécanique, 1969, depois em alemão em 1972, Mensch und Maschine als Übersetzer, Application of mathematical models and computers to linguistics, 1976); Kulmanova aborda temas frequentes relativos à tradução;

- 1968: Kovahnuk se interessa pela prática da tradução;

- 1969: Eligulašvili, $V$ originale $i$ v perevode, mostra um interesse particular na apresentação comparada de textos-fonte e alvo;

- 1971, 1972: Koptilov publica dois trabalhos bastante conhecidos Aktual'ni pytanňa chudožňoho perekladu, e Peršotvir i pereklad;

- 1973: Ganev, Komissarov (Slovo o perevode. Očerk lingvističeskogo učenija o perevode e, em 1980, apresenta uma abordagem linguística à tradução), Kundizic, Martinova;

- 1974: Retzker publica um estudo sobre a teoria e a prática da tradução;

- Regras de tradução para textos literários, enunciadas pelo pesquisador eslovaco A. Popovič (1975), Teória umeleckého prekladu (Theory of literary translation), vão historicamente dos princípios da tradução prescritivos e descritivos de Katarina Reiss (1971), Möglichkeiten und Grenzen der Übersetzungskritik, os teoremas da tradução de J.-R. Ladmiral (1979), Traduire: théorèmes de la traduction, aos estudos da escola de Tel Aviv ${ }^{9}$ (Gideon Toury, Jose Lambert), e a teoria dos polissistemas (Holmes, Even-Zohar).

- A contribuição e influência ${ }^{10}$ de Coşeriu (1976) nos estudos da tradução está manifesta na teoria do texto e no estudo Lo erróneo y lo acertado en la teoría de la traducción, ${ }^{11}$ que lança luz nas teorias linguísticas gerais sobre tradução e é considerado um ponto crucial na distinção entre a ciência linguística da tradução 
e os estudos da tradução. Embora as ideias de Coşeriu sejam citadas por linguistas americanos como M. Shapiro, R. Antilla e John Lyons, sua falta de impacto no mundo anglófono pode ser causada pelo fato de os trabalhos fundamentais de Coşeriu ainda não terem sido traduzidos, o que traz à nossa atenção a necessidade de traduzir os estudos da tradução, o que pode ser a razão pela qual tantos pesquisadores da Europa do Leste não serem conhecidos;

- O estudo Neperevodimoe v perevode (1980, A intraduzibilidade na tradução) dos autores búlgaros Sergej Vlahov e Sider Florin, que tiveram dez edições entre 1980 e 2012, segue de perto essas reflexões pioneiras.

No entanto, podemos falar hoje em uma influência polissistêmica dos estudos da tradução, de uma recepção voltada exclusivamente para os estudos alóctones e da sua aplicação em relação a traduções específicas, ou em pesquisa espelho. Assim, a pesquisa teórica fundamental, como a de Peirce, por exemplo, tem uma influência semelhante sobre os autores ocidentais e orientais: Cosculluela, Traductologie et sémiotique peircienne: l'émergence d'une interdisciplinarité (1996), Iordache, Semiotica traducerii poetice [A semiótica da tradução poética] (1993) e Condrea, Traducerea din perspectivă semiotică [Tradução a partir de uma perspectiva semiótica] (2006). Em vários trabalhos recentes, os pesquisadores se concentram em assimilar as teorias ocidentais, particularmente em francês e inglês, mas também alemão, suas bibliografias exibindo apenas poucas obras de seu espaço linguístico de origem.

A motivação desses autores está enraizada no respeito que têm pelos modelos ocidentais emprestados, que desejam implementar na pesquisa sobre tradução, in statu nascendi em seu país de origem. Esse é o caso de vários trabalhos sobre a didática da tradução, voltados para o ensino e/ou aprendizado da teoria da tradução ou da própria tradução, publicados em francês (por exemplo, ${ }^{12}$ na Romênia, A. Rădulescu, Théorie et pratique de la traduction (2005)); na Moldávia Exégèse et traduction littéraire. Méthode de formation en traduction littéraire (2005) e Théorie et pratique de la traduction (2007) de A. Guțu; na Bulgária, Pour comprendre la traduction (2009), de I. Kristeva, ${ }^{13}$ assim como trabalhos sobre o pensamento dos estudos da tradução, também publicados em língua estrangeira, como Introduction à la traductologie française (2008) e Écrits traductologiques (2012) de Guţu, Bref aperçu des grands courants en traduction, écoles européennes et américaines (2008) por A. Rădulescu. Embora o público seja limitado aos usuários da língua francesa, a utilidade didática de tais obras é inegável, assim 
como a capacidade de síntese de seus autores. Na Moldávia, I. Condrea expande ainda mais as perspectivas linguísticas na abordagem da tradução Traducerea din rusă înromână [Traduzindo do russo para o romeno] (1999), Comunicarea prin traducere [Comunicação pela tradução] (2001), Semiotica textului artistic tradus [Semiótica do texto artístico traduzido] (2003). Há também situações mais abertas à recepção, quando publicações estrangeiras, que também funcionam como livros didáticos para estudantes, são muitas vezes duplicadas por publicações (livros e artigos) na língua materna dos autores. ${ }^{14}$ Assim, os destinatários classificam-se em duas categorias: especialistas e tradutores em formação.

\section{[A] Perspectivas nos estudos da tradução romenos}

\section{[B] Linhas de pesquisa nos estudos da tradução romenos}

A diversidade dos estudos teóricos realizados por autores romenos permite uma classificação em várias categorias que abordam: a) o estudo da tradução como um processo e/ou como produto; b) a análise dos métodos de tradução; c) a crítica do texto traduzido. Dependendo dos parâmetros considerados, linguísticos ou extralinguísticos, textuais ou culturais, a pesquisa

110 em tradução na Romênia segue uma das linhas mencionadas anteriormente, seja em trabalhos extensos, seja por meio de estudos breves.

A seguir, vamos apresentar alguns exemplos relevantes das linhas de pesquisa seguidas pela pesquisa romena no campo dos estudos da tradução. Tal apresentação é inevitavelmente fragmentária (não poderia ser holística), mas, embora limitada por restrições materiais, pretende ser imparcial.

Devemos também mencionar, por razões de fácil compreensão, que não podem ser abordadas aqui, o interesse demonstrado pelos pesquisadores por textos relacionados aos estudos da tradução, cujo impacto é bastante significativo para a nossa área de pesquisa. A partir da tradução

- parcial (Mounin, Linguistic Problems of Translation, nos anos 1970);

- anônima (Fedorov, Introduction to the Theory of Translation, 1972);

- ou integral, de algumas obras de referência (Steiner, După Babel. Aspecte ale limbii și ale traducerii, 1983, traduzida por Negoiță and Avădanei),

Tradutores e teóricos têm demonstrado interesse em formar e informar, não em padronizar o gosto dos tradutores, e os teóricos têm demonstrado interesse em formar e informar, não padronizar, o gosto do público-alvo, tanto de leitores experientes quanto do 
público em geral. Assim, numa área em que o bilinguismo funciona por necessidade, a tradução de textos relacionados aos estudos da tradução, embora não tenha um impacto primordial nas ideias romenas dentro do campo, permite o acesso e o conhecimento sobre a pesquisa de outras áreas linguísticas. Alguns exemplos:

- 2000: R.T. Bell, Teoria și practica traducerii (Translation and Translating: Theory and Practice), tradução de Gazi;

- 2001: a Hermeneutica de Schleiermacher, tradução de Râmbu;

- 2005: Terminologia traducerii (Terminologie de la traduction /Translation terminology) de Delisle, Jahnke and Cormier, tradução de R. e L. Baconsky;

- 2006: Ricoeur, Despre traducere (Sur la traduction), tradução de M. Jeanrenaud;

- 2008:

- Humboldt, Wilhelm von, Despre diversitatea structurală a limbilor omeneşti şi influenţa ei asupra dezvoltării spirituale a umanităţii (Sobre a língua: a diversidade da estrutura da linguagem humana e sua influência no desenvolvimento mental da humanidade); tradução de E. Munteanu;

- U. Eco, A spune cam acelaşi lucru (Dire quasi la stessa cosa), tradução de Laszlo;

- J. Delisle e J. Woodsworth (coord.), Traducătorii în istorie (Les Traducteurs dans l'histoire), 2008, tradução coordenada por Lungu-Badea;

- 2011: M. Ballard, Numele proprii în traducere (Le Nom propre en traduction), tradução coordenada por Lungu-Badea.

\section{[C] Tradução, linguística contrastiva e didática da tradução}

A tradição da pesquisa na Romênia é expressiva, os pesquisadores são muitos, mas seus nomes são pouco conhecidos: I. Eliade (1970, 1971, 1973); L. Leviţchi (1975), A. Baciu \& V. Baciu (1980), T. Cristea (1981, 1987, 1998); J. Drăghicescu (1989); A. Bantaș (1998); Bantaș \& E. Croitoru (1999); A. Cuniţă (1999a, 1999b); A. Rădulescu (2005) e M. Constantinescu (2002) (LUNGU-BADEA, 2005, [2013]/2015). Após breves introduções à teoria da tradução, estes autores propõem exercícios de tradução que requerem certa estratégia de tradução, o que, por sua vez, pede métodos de tradução específicos. São estudos normativos ancorados na área da linguística contrastiva ou na metodologia de ensino de língua estrangeira, ${ }^{15}$ que afirmam claramente seu propósito didático: desenvolver e aprimorar a competência tradutória. Em vários níveis, os estudos romenos dedicados à tradução trazem a influência ocidental ou ecoam sincronicamente essas tendências. ${ }^{16}$ 
Rompendo com os padrões nacionais, a obra de L. D. Levițchi, modestamente chamada Indrumar pentru traducătorii din limba engleză în limba română [Guia para tradutores do inglês para o romeno], posteriormente chamado de manual, é um autêntico vade-mécum para tradutores. Um trabalho de estabelecimento de normas e uma ponte entre épocas e métodos, o guia reúne e capitaliza os princípios da tradução dentro da língua inglesa desde John Dryden até ao presente. É um dos mais robustos e sutis defensores da melhoria das línguas utilizadas pelo tradutor, para que a leitura do texto-fonte possa ser feita com um "olho linguístico" (LEVIŢCHI, 1975, p. 252). Não é ainda uma "leitura tradutológica".

O objetivo de tais estudos de definição de normas é melhorar o processo real de tradução e melhorar a qualidade da própria tradução, detalhando o processo de transferência linguística.

\section{[C] Reflexões teóricas sobre o fenômeno da tradução, a condição do tradutor e os estudos}

\section{da tradução; crítica de tradução}

Com raízes profundas nos textos prototradutológicos do século XIX (KOGĂLNICEANU, 1837, 1840; MAIORESCU, ([1878]/1966), IORGA, 1936, e outros), a crítica de tradução e de

112 reflexões sobre o estabelecimento de normas têm surgido constantemente como uma reação contra a tradução vista como violação da língua. As laboriosas análises filológicas centram-se no texto-alvo, observando respeitosamente o modelo bilíngue de avaliação e relação com o texto original. A tradução indireta tem sido criticada por suas limitações implícitas. ${ }^{17}$ Tais corrupções e deturpações produzidas por qualquer texto-alvo forçado a tornar-se fonte de uma tradução subsequente foram analisadas por N. Cartojan, E. Munteanu or N. A. Ursu (as Confissões de Voltaire traduzidas por Guerassim e a tradução de uma história dos EUA). Os tradutores são influenciados por sua própria fonte, seja original seja intermediária (URSU, 1986, p. 4).

Denunciadas por meio de artigos descritivos, as deficiências da tradução direta e/ou indireta são acompanhadas pelo estabelecimento de normas e por reflexões cognitivas sobre o processo de tradução. Como ponto de partida necessário, "o velho mito da Torre de Babel”, com as suas várias lições, é a base escolhida por Henri Jacquier (1991, p. 124-215) para construir sua análise do processo de tradução e de suas fases. A “denúncia” é menos importante do que o fenômeno em si, comparável e definível nos termos dos polissistemas de Even-Zohar (1974): a tradução, resultado de uma ação de transferência interlingual, logo, a totalidade dos textos traduzidos (majoritariamente literários), encarna um sistema, quase autônomo em relação ao sistema doméstico (literário, científico, etc.). 
Vamos sair dos limites da tradução para os limites dos estudos da tradução, a fim de defini-los. Desde o final dos anos 1970, podemos falar de estudos da tradução na Romênia. Após estudar equivalentes de tradução (KOHN, 1976; GHIŢĂ, 1978), Elena Ghiţă (1980, p.443-447, 1999 p. 5-15) se concentra em seus estudos na terminologia e no status dos estudos da tradução, as tendências e linhas de estudos da tradução ocidental, além do objeto de pesquisa (traduzibilidade e não tradução, 1995, p. 5, ver também KOHN, 1979). A autora chama a atenção para os vários objetivos dos estudos da tradução, bem como para os vários conceitos que criam a metalinguagem da tradução (GHIŢĂ 1982, p. 63-72, 1983, p. 61-67), e sintetiza as principais estratégias de tradução (GHIȚĂ 1982, p. 193-198). Também podemos encontrar observações a respeito das limitações dos estudos da tradução, como teoria, ciência e disciplina (IONESCU, 1989, 2000).

\section{[C] Tradução a partir de uma perspectiva diacrônica ${ }^{18}$ e sincrônica, história da tradução}

Mencionaremos apenas obras que pertençam explicitamente à esfera da tradução e dos estudos da tradução. A análise diacrônica de textos bíblicos no âmbito dos estudos da história da língua romena antiga e moderna, a pesquisa comparada e contrastiva, lexicológica, terminológica, etc., tornaram-se generosos objetos de pesquisa. Podemos encontrar páginas relacionadas à história e à meta-história da tradução escritas por N. Cartojan, P. Cornea, N. A. Ursu, V. Cândea, E. Coșeriu, E. Munteanu, e outros.

Cornea (1966, p. 56) mostra que o problema da exatidão é imperceptível nos séculos XVIII e XIX, quando predominavam a flexibilidade do conceito de propriedade literária e o cuidado de não assustar o leitor. Os tradutores tomaram grandes liberdades com o texto-fonte: omissões, interpolações, alterações de estilo, interpretações. Naquele momento, a tradução e a traição eram como mão e luva feita sob medida.

O interesse de Cândea nas origens da história da tradução se materializa em um estudo sobre um respeitado estudioso romeno: Nicolae Milescu şi începuturile traducerii umaniste în limba română [Nicolae Milescu e os primórdios da tradução humanista na Romênia] (CÂNDEA, 1963, p. 29-76). O autor mostra que o texto final foi corrigido devido à interpretação correta das primeiras traduções do Antigo Testamento, que o tradutor usou a Septuaginta como texto-fonte (a edição de Frankfurt am Main, 1587) e, como versões auxiliares para autoverificação, também usou a tradução eslava da Bíblia (Ostrog, 1581), a Vulgata e outras traduções latinas do texto original em hebraico. 
Coseriu $^{19}$ examina a evolução linguística de uma língua através de traduções, começando como as versões romenas do Pai Nosso, publicadas em coletâneas ocidentais em 1580, depois em Gilbert Genebrard, em Cronographiae libri quator, Paris, Andréas de Poza, 1587, Bilbao, Claude Duret, 1613, Cologne, Martin Optiz, 1623, Stephen Skinner, 1671. O linguista destaca os mais importantes registros em língua romena em documentos ocidentais, pelo pesquisador sueco Georg Stiernhielm, no prefácio intitulado De linguarum originae à sua tradução de Ufilia (1671). O Pai Nosso é apresentado em latim e em outras sete línguas românicas (itálico, hispânico, galego, rético, sardo, sardo vulgar, valáquico), e o autor é o único a considerar a língua romena (valáquico) como uma língua românica separada, e não um dialeto de outra língua românica.

Em Studii de lexicologie biblică [Estudos de lexicologia bíblica], um trabalho substancial sobre a história da tradução, E. Munteanu (1995) centra-se nas interferências linguísticas entre o romeno e as línguas clássicas que se manifestam na tradução de textos religiosos no século XVII, o século das traduções religiosas mais significativas. O autor enfatiza o apogeu da criatividade lexical, imposta pela necessidade de lexicalizar novos conceitos no 114 espaço intertextual da tradução e aplica, na sua própria análise lexicológica, a teoria da designação, significação e sentido de Coşeriu (MUNTEANU, 1995, p. 6).

O autor leva em conta o ambiente cultural no momento da conclusão e da recepção da tradução bíblica, compara traduções aos textos originais (grego, eslavo, latino) e observa que a estratégia da tradução literal foi considerada a única forma de preservar a sacralidade do texto bíblico (MUNTEANU, 1995, p. 11); usando esta técnica, a prática da tradução para o romeno segue a tradição das traduções medievais da Bíblia: a língua vernácula romena foi enriquecida pelo literalismo, uma imitação sancionada pela prática litúrgica (MUNTEANU, 1995, p. 11) que levou à criação de um idioma artificial de tradução.

Os textos analisados por Munteanu (1995) de forma comparativa são traduções reais de traduções da língua hebraica. O autor pretende estudar: as interferências linguísticas entre a língua romena e as línguas clássicas culturais atuais - grego, eslavo e latim; o século XVII; e identificar os métodos pelos quais os tradutores romenos traduzem a realia percebida em grego pelas significações que a língua romena oferecia naquele momento específico. (MUNTEANU, 1995, p. 6).

O método de avaliação comparativa das traduções, derivado do modelo textual (MUNTEANU, 1995, p. 8-9), revela as renovações semânticas e sua evolução através das sucessivas versões do texto bíblico, a natureza popular ou acadêmica de certas inovações, bem 
como a especialização semântica de outras. A investigação interlinguística comparativa também é aplicada a outros fatores não linguísticos: o horizonte cultural do tradutor, suas habilidades linguísticas e seu conhecimento da tradição literária romena, o grau de precisão em relação ao texto original, sua visão da função cultural e especificidade da tradução, o uso de instrumentos filológicos (várias edições, glossários, etc.), a fim de compreender qualquer evolução semântica. Uma análise comparando textos traduzidos para o romeno no século XVII com os textos gregos, que eram traduções intermediárias do hebraico, confirma a suposição de que "os tradutores medievais não tinham uma compreensão definida, coerente, precisa e sistemática dos princípios da tradução" (MUNTEANU, 1995, p. 36). Além dessas análises comparativas, o estudo também inclui depoimentos de tradutores em exercício, perspectivas incipientes, tentativas tímidas de justificar, não regular, o processo de tradução (MUNTEANU, 1995, p. 93).

\section{[C] A teoria da tradução e a influência da teoria literária}

Escritores, críticos, teóricos, tradutores têm meditado sobre esse tipo particular de experiência artística que é a tradução literária (BLAGA, 1957; PERPESSICIUS, 1957; FLORA, 1970; GHEORGHE, 1972; GHIŢĂ, 1979, 1994, 1998, 2005; MAVRODIN, 1981; KOHN, 1979; MICLĂU, 1983; LOGHINOVSCHI, 1989; MARCUS, 1984).

A eficiência da aplicação de princípios e métodos específicos da linguística contrastiva à poesia é muito mais problemática do que a sua aplicação à prosa ou a romances, que eram traduzidos em função do assunto, como se a técnica não fosse um fator elementar, e sim adicional, estético, opcional. No caso da poesia, a sutileza e a diversidade de métodos de análise permitiram condicionar a "transcriação" a uma disposição de elementos relacionados com a forma, a prosódia, o ritmo e a versificação, etc. Nem a poesia e o seu discurso vigoroso, nem a prosa e o seu discurso expressivo funcional podem ser reduzidas à soma total das técnicas de construção ${ }^{20}$ e excedem a venerável disputa de forma versus conteúdo, já que o que está sendo comunicado não deve contradizer a forma de comunicação.

Com seu Virtuţile compensatorii ale limbii române în traducere [Características compensatórias da tradução romena] Ioan Kohn (1979) restabelece um equilíbrio entre os estudos dedicados às limitações da tradução, que constituem "a literatura desafiadora da tradução" e os estudos dedicados ao enriquecimento de textos por meio da tradução, para "o que a obra literária ganha com a tradução, que pode compensar, parcial ou totalmente, as insuficiências obrigatórias" (KOHN, 1979, p. 5); o autor demonstra que, na verdade 
o verdadeiro problema não reside na afirmação ou na negação de uma atividade que a prática da tradução - impressionante, tanto em termos de qualidade como de quantidade - reconhece (desafios, por mais sutis e "rigorosos" que sejam, permanecem puramente teóricos), mas na compreensão das limitações e dificuldades inerentes ao processo de tradução, na determinação da probabilidade de erro e na explicação científica dos princípios da traduzibilidade. (KOHN, 1979, p. 39).

Superar desafios e dificuldades de tradução pressupõe conhecê-los, e é por isso que Kohn classifica os paradoxos provenientes da (in)traduzibilidade em duas categorias, estética e linguística (em Catford, linguística e cultural). Kohn divide as questões linguísticas em mais duas classes: estritamente linguística, desencadeada pelas diferentes representações da realidade; e não linguística ou cultural (1979, p. 39, 45), endossando a opinião de Georges Mounin $^{21}$ de que "a intraduzibilidade não deve ser considerada como um mistério ou um espantalho: é um conceito estático".

Kohn enfatiza o papel do contexto, que pode atualizar continuamente a expressividade de uma palavra e recompor a "cadeia funcional" original, mas também restaurar os recursos latentes da língua-alvo (JAKOBSON, 1959), aquelas "virtualidades que se tornam elementos compensatórios altamente eficientes" (KOHN, 1979, p. 52). Embora defensor da traduzibilidade absoluta e da recriação pela tradução, Kohn conclui:

\footnotetext{
É impossível preservar todas as nuances estilísticas na tradução: em termos de som, estrutura gramatical, estrutura lexical, cada idioma tem seus próprios valores estéticos, muitas vezes por razões extralinguísticas, e por vezes pode ser impossível recompôlos de forma idêntica. Além disso, devido às novas virtudes, aquelas da linguagem da recepção, a mensagem artística original ganha, por meio da tradução, uma espécie de força que é por vezes superior à original e que, por tais "vitórias", compensa as falhas em outro lugar. (KOHN, 1979, p. 259).
}

O autor evoca as limitações impostas pelo sistema linguístico e as limitações individuais do tradutor, que é chamado a ultrapassar tais limitações, introduz a compensação e a criatividade como métodos de consolidação de um sistema de avaliação e faz uma distinção entre a traduzibilidade do sentido geral ${ }^{22}$ e a compensação de valores estilísticos (KOHN, 1979, p. 258 e modelos de avaliação). Nesse sentido, uma abordagem complementar e multifacetada da tradução pode revelar-se útil, além da abordagem linguística.

Das limitações da língua e do tradutor, passamos ao potencial interpretativo do leitor. Em Traducerea, o practico-teorie [Tradução: uma teoria prática], Irina Mavrodin (1981, p. 191209) identifica tipos opostos de leitura, dependendo do horizonte de expectativa do leitor (ver ECO e SPENGLER); assinala que a "leitura única e final" se opõe à "leitura historicamente 
situada" e, portanto, a tradução única se opõe à tradução que leva em conta a historicidade (o que significa que ela se desdobra em referência à funcionalidade e fidelidade, segundo Benjamin (1921) ou Berman (1985)). A tradução deve ser um tipo de leitura plural e, se encarnar apenas um tipo de leitura, torna-se infiel à obra e ao leitor, que se vê privado das interpretações latentes que estão na base da intenção comunicativa do autor. A avaliação do discurso de Mavrodin sugere que a tradução deve também refletir a subjetividade do tradutor.

No seu discurso, os tradutores de poesia destacam, ao seguirem o modelo britânico, a empatia que deve existir entre o tradutor e o autor. Ciente de que os poetas privilegiam o significado em detrimento do significante, Miclău (1981, p. 71-78) afirma que a fase primária da tradução da poesia deve visar preservar as conquistas semânticas do artista, e a fase secundária deve centrar-se na revisão da prosódia com o intuito de recuperar as estruturas de versificação, rima e métrica. Em Signes poétiques, Miclău $(1983$, p. 6) destaca a ideia de que a admissão de múltiplas leituras nos situa no contexto do globalismo, e de que tal leitura é um elemento do todo. A tradução de poesia requer um tipo especial de leitura, "un travail de réflexion, d'interprétation, de réflexion et de rédaction" ["um trabalho de reflexão, de interpretação, de reflexão e edição"] (MICLĂU, 1983, p. 10). O autor romeno, seguindo Haroldo de Campos, e alinhado com os estudos que seriam publicados por Inês Oseki-Dépré, delimita a tradução da poesia ao campo da poética e da semiótica, respectivamente (MICLĂU, 1983, p. 223). Se o poeta "écoute la langue du coeur" ["escuta a linguagem do coração"], o tradutor terá como foco a "transposition en code linguistique du flux de la sensibilité" [“transposição do fluxo da sensibilidade em código linguístico"] (MICLĂU, 1983, p. 230).

Outro aspecto dos estudos da tradução romenos é a dependência do texto a ser traduzido em relação ao idioma de origem. Assim, S. Marcus (1984, p. 288-296) mostra que elementos e estruturas unívocos, com alto grau de determinação, são facilmente transferidos de uma língua para outra, permanecendo intactos independentemente da direção da tradução (de ou para a língua materna). Além dos textos que são de alguma forma independentes da língua romena (por exemplo, M. Sorescu), S. Marcus (1984, p. 290) menciona certos textos marcados pelo gênio da língua romena e, consequentemente, considerados intraduzíveis (como a poesia de Eminescu, por exemplo). A intraduzibilidade continua a variar em função do grau de hospitalidade da língua-alvo (por exemplo, Eminescu é mais bem recebido pela língua alemã do que pela língua francesa). Indiretamente, a intraduzibilidade de Marcus reflete o conceito binário de Catford de tradução (total versus restrita) e de intraduzibilidade (linguística e cultural). 
E. Loghinovski (1989, p. 9-10) mostra que o problema da intraduzibilidade, particularmente do ponto de vista artístico, excede as descrições estritamente científicas e incorpora questões éticas. As equivalências relativas entre línguas - vistas como sistemas, que ecoam as equivalências de Fedorov, Smirnov - de alguma forma permitem a transferência de uma língua para outra, ao descartarem o ponto de vista formal e aceitarem o extralinguístico e o macrolinguístico, abrindo-se para campos de estudo adjacentes, numa abordagem comparativa (LOGHINOVSKI, 1989, p. 14). Este é também o lugar para estudos poéticos contrastivos, que o autor desenvolve em suas análises dedicadas às traduções russas da poesia de Eminescu.

\section{[B] Novas linhas de pesquisa na Romênia}

A expansão dos estudos de doutoramento após 1990 explica a abundância de pesquisas no campo dos estudos da tradução. Durante a era pós-revolução, o desenvolvimento de atividades de tradução tem sido incentivado por várias instituições culturais, nem todas nacionais. Esse desenvolvimento levou ao crescimento de um aparato crítico mais rigoroso. Dependendo de seu

118 foco, a pesquisa de doutorado poderia ser agrupada em teses que revisitam temas clássicos, ou seja, examinam linguagens em contraste e em contato, tanto em trabalhos poéticos quanto fora deles $^{23}$ e, a partir dos anos 1990, teses cujos autores colocam suas próprias pesquisas dentro do marco teórico geral dos estudos da tradução.

- E. Iordache em Semiotica traducerii poetice [Semiótica da tradução poética] apresenta de forma sintética as teorias da tradução do início dos anos 1950 até o início dos anos 1990 e um estudo de caso de algumas versões estrangeiras de poemas romenos. C. Petrescu tem uma abordagem similar em Traducerea între realizare poetică şi semiotică [Tradução entre a realização poética e semiótica]. Consiste numa breve introdução à história da tradução e dos estudos da tradução, seguida de uma análise comparativa bilíngue aplicada da tradução de um poema e da tradução em prosa;

- E. Cleynen-Serghiev (1993) investiga as restrições e liberdades de tradução do período entre as duas guerras mundiais na tese "Les belles infidèles" en Roumanie. Les traductions des ouvres françaises durant l'entredeux-guerres (1919-1939) [“As belas infiéis” na Romênia. As traduções de obras francesas no período entreguerras (1919-1939)]; 
- R. Dimitriu (2001) concentra-se em várias dissociações e interferências tradutórias em Disocieri şi interferenţe în traductologi [Dissociações e interferências na tradução] e também escreve Translation Theories and Practice [Teorias e prática da tradução] em 2002;

- A obra Orizontul traducerii [Horizonte da tradução] é reeditada em 2004;

- Um trabalho fundamental na atual pesquisa romena em tradução é Universaliile traducerii. Studii de traductologie de M. Jeanrenaud (2006). O autor investiga questões gerais e específicas relativas à tradução entre linguagens, estratégias e técnicas relacionadas, a reformulação e deform(ul)ação pela tradução, a relação entre o autor e o tradutor, e questões de direitos autorais.

- Inserido na categoria de estudos literários, possivelmente devido ao título, que faz o leitor pensar em adaptação - que não é nada senão crescente -, Un caftan pentru Don Quijote [Um caftan para Dom Quixote] contém elementos de várias naturezas: poética, hermenêutica, filosofia, etc. Partindo da linguística contrastiva, V. Ivanovici (2011) tenta delinear uma "poética de tradução" e fundamenta sua abordagem na relação entre texto e traduzibilidade, entre estudos da tradução, filosofia e, necessariamente, filosofia de tradução, bem como na conexão entre intertextualidade e análise estrutural. Partindo da linguística contrastiva, V. Ivanovici (2011) tenta delinear uma "poética da tradução" 24 e fundamenta sua abordagem na relação entre texto e traduzibilidade, entre estudos da tradução, filosofia e, necessariamente, filosofia da tradução, ${ }^{25}$ bem como na conexão entre intertextualidade e análise estrutural. A investigação do autor sobre o processo de tradução conduz à desmistificação desse ato tanto complacente quanto desafiador. $\mathrm{O}$ autor propõe não apenas uma poética da tradução, mas também outros pontos de referência, de outra natureza. Assim, ele segue tanto a tradição da poética da tradução realizada por Henri Meschonnic, acrescentando-lhe deliciosos detalhes específicos das traduções para o romeno, quanto a dos estudos da tradução em geral. Os teoremas de Ivanovici ecoam um inevitável ponto de referência na área da tradução, Traduire: théorèmes pour la traduction, ${ }^{26}$ de J.-R. Ladmiral, mas suas hipóteses sugerem um comparativismo balcânico. ${ }^{27}$ 
Além dessas ideias presentes em artigos e estudos antes do novo milênio, a pesquisa está se expandindo sobre aspectos específicos, como a intraduzibilidade e o interculturalismo, a história da tradução, a metalinguagem dos estudos da tradução, ${ }^{28}$ em vez de generalizar a abordagem descritiva e normativa.

A relação entre tradução, estudos da tradução e estudos culturais é outra linha seguida pela pesquisa atual na área. A monografia sobre adaptação, proposta na tese de doutorado Implications socio-culturelles dans l'acte traductif: l'adaptation, de M. Codleanu (2002) (Universidade "Ovidius", Constanţa) parte da definição de adaptação como um método de tradução e faz um inventário de suas várias técnicas. $O$ autor utiliza um conceito que é controverso nos estudos da tradução devido à sua falta de especialização rigorosa. A tradução como espaço de negociações significativas, que remete a Umberto Eco, é também abordada por I. Mihalache (2002) em Traduction et représentations: discursivité du "modèle occidental" dans la Roumanie post-communiste (Universidade de Laval). Seguindo o modelo dos polissistemas, o autor investiga o modelo ocidental de tradução tomado de empréstimo pela Romênia pós-1989. O corpus multidisciplinar (coedições anglo-romenas ou franco-romenas)

120 está sendo utilizado para mostrar que o modelo descritivo da tradução é o único que, na opinião do autor, pode permitir a compreensão e a descrição de como funcionam as traduções e o processo de escrita, sem fingir emitir qualquer juízo de valor.

Em Contextul extralingvistic în traducerea culturemelor. Cazul limbilor franceză şi română [O contexto extralinguístico na tradução de culturemas: o caso do francês e do romeno], 2003, e, subsequentemente, em Teoria traducerii, teoria culturemelor [Teoria da tradução, teoria dos culturemas], 2004, examinamos a tradução a partir da perspectiva do culturalismo comparado (o lado descritivo dos estudos da tradução) com vistas a oferecer uma série de reflexões específicas (o lado normativo da pesquisa) e uma análise unitária baseada em quadros teóricos rigorosos e bem definidos apropriados para o objeto de investigação (tradução como processo e produto acabado) (LUNGU-BADEA, 2004). Situamos a avaliação da tradução a partir da perspectiva da transferência cultural dentro da teoria do culturema e localizamos o culturema e os problemas levantados pela sua tradução dentro do quadro geral da disciplina, numa tentativa de destacar um modelo/protótipo de tradução (o lado prospectivo de nossa pesquisa). Pesquisas teóricas dedicadas à definição do conceito de culturema foram realizadas por Poyatos (1979), Oksaar (1988), Vermeer e Witte (1990), Sandrini (1999), Vermeer (1997) e Chesterman (1999). Tentamos pintar um quadro exaustivo do fenômeno dos culturemas na tradução, apresentando-os dentro de um sistema, acompanhados pela descrição das conexões 
entre os componentes desse sistema: definição; significados do termo em outras áreas de pesquisa; como funcionam no campo real da tradução; delineamento teórico e prático e seu lugar nos estudos da tradução, juntamente com outros tipos de teorias da tradução.

A transferência interlingual de particularidades culturais é tratada por R. Dimitriu (2006) em The Cultural Turn in Translation Studies [A virada cultural nos estudos da tradução], enquanto em Traducerea şi lexicul fără echivalent: român-englez [Tradução e a lacuna lexical romeno-inglês], J. Moise (2006) contextualiza e descontextualiza o elemento e, na esteira de Jakobson e de autores como I. Evseev e V. Şerban (1978), ${ }^{29}$ revitaliza e propõe soluções para novas estruturas (lexicais, fraseológicas, culturais, etc.), muitas vezes incluídas por vários autores na categoria da lacuna lexical, e investiga a intraduzibilidade delas.

Os pesquisadores romenos também não evitam a área de crítica de tradução: $M$. Constantinescu (2013) pleiteia Pour une lecture critique des traductions [Por uma leitura crítica das traduções].

Devemos notar que as teses de doutoramento abordam vários aspectos dos estudos da tradução, da sociologia e história recentes da tradução romena contemporânea, inseridas na Europa Oriental (I. Popa (2004), La Politique extérieure de la littérature. Une sociologie de la traduction des littératures l'Europe de l'Est (1947-1989)), aos estudos focados em épocas ideologicamente marcadas (D. Măriucuţa (2011), Traduire pour le peuple. Réception de la littérature française en Roumanie de 1948 à 1965, Universidade de Bucareste), às técnicas de tradução e excursões à metalinguagem da disciplina (A. Coiug (2010), André Baillon en roumain. Une lecture traductologique, Universidade de Cluj) ou aos estudos culturais (A. Pelea (2010), Aspects culturels dans la traduction des contes populaires du roumain vers le français et du français vers le roumain, Universidades de Cluj e Arras).

$\mathrm{O}$ aumento do número de traduções e retraduções ${ }^{30}$ tem atraído um número crescente de pesquisadores, que têm se dedicado a problemas relacionados à tradução de gêneros específicos $^{31}$ e a certas dificuldades contextuais. ${ }^{32}$ Alguns têm publicado artigos e livros didáticos relacionados aos desafios colocados pela tradução entre pares específicos de línguas, ${ }^{33}$ a problemas específicos da retradução e/ou da subjetividade do tradutor (C. Tiron, C. Hetriuc, e outros, em várias edições do periódico Atelier de traduction) e à distorção dos significados devido ao excesso ou à falta de pudor (I. Nănău-Cosma (Translationes 2010, 2012)), e assim por diante.

O inventário e a cartografia do interesse pela tradução e pelos estudos da tradução não estariam completos sem mencionarmos os eventos científicos dedicados ao fenômeno, na 
Romênia ou na Áustria. Os anais desses eventos reúnem trabalhos sobre problemas específicos da tradução e dos estudos e tradução, a partir de: desafios estéticos e linguísticos (J. Foucault e M. Constantinescu (coord.), 2007, Lire et traduire la littérature de jeunesse, Lungu-Badea, Pelea e Pop (coord.), 2010, (En)Jeux de la traduction...); métodos de ensino e pesquisa em tradução (Lungu-Badea, 2013, De la méthode en traduction et en traductologie; Lungu-Badea e Pelea (dir.), 2015, Enseigner et apprendre à traduire de "façon raisonnée”); e história da tradução romena (Jeanrenaud et al. 2014: "Traducerile au de cuget să îmblînzească obiceiurile..." Rumänische Übersetzungsgeschichte - Prozesse. Produkte. Akteure; e das obras coletivas editadas por Lungu-Badea: Études de traductologie roumaine. I Discours traductif, discours métatraductif, 2017a; Études de traductologie roumaine II. Essai de cartographier la recherche roumaine, $2017 \mathrm{~b})$.

$\mathrm{O}$ interesse pela história da tradução romena ultrapassou as fronteiras nacionais. ${ }^{34} \mathrm{As}$ obras de historiadores e historiógrafos da tradução romena constituem fundamentos teóricos e práticos analisados por H. Lenz (2012) em sua expressiva seção dedicada à história da tradução romena, dentro da obra coletiva Histoire de la traduction en Europe meédiane [História da

122 tradução na Europa Central]. ${ }^{35}$ M. Ballard (2013) também inclui a história da tradução romena ${ }^{36}$ em sua Histoire de la traduction. Repères historiques et culturels [História da tradução: marcos históricos e culturais]. ${ }^{37}$ Uma abordagem histórica e historiográfica também é proposta por L. Schippel (2012) em Die Übersetzungskultur in Rumänien.

\section{Conclusões}

Um levantamento dos estudos da tradução romenos poderia ser útil para o desenvolvimento de uma base de dados europeia e poderia tornar-se o principal objeto e objetivo de um grupo de pesquisadores em estudos da tradução. Como resultado do nosso próprio exame, temos de notar que os estudos da tradução romenos, como parte dos estudos da tradução na Europa Central, são menos baseados em reflexões linguísticas e de tradução articuladas dentro da área nacional, e mais centrados em teorias da tradução estrangeiras e ocidentais.

A compreensão da tradução e o desenvolvimento dos estudos da tradução dentro de uma área linguística específica não pode ser fundada apenas na revisão de teorias ocidentais de renome, citadas na maioria dos estudos publicados em todo o mundo. Referir-se a tais teorias é importante, mas é igualmente essencial aplicá-las com o devido respeito às particularidades de tradução de cada língua. Portanto, há necessidade de que os trabalhos de estudos da tradução 
sejam publicados também na língua materna dos pesquisadores. ${ }^{38}$ Escrever em outro idioma que não o seu, descrevendo e sintetizando informações comuns para a língua de publicação, não promove a pesquisa nacional nem desenvolve a internacional; apenas mostra que o autor tem conhecimento sobre o que foi escrito em determinada área dos estudos da tradução (principalmente didático, algumas vezes histórico, outras vezes teórico, etc.).

No espaço da Europa Central, bem como no espaço da Romênia aqui investigado, podemos falar de várias formas de realizar estudos da tradução: 1) explorar a história dos estudos da tradução ocidental, reunindo seleções inspiradas e apresentações sintéticas de qualidade; 2) aplicar teorias estrangeiras à pesquisa nativa em tradução, com vistas a desenvolver uma consciência da tradução e a construir a disciplina de estudos da tradução sobre uma base realista; 3) ignorar parcial ou completamente os estudos da tradução ocidentais em um recuo etnocêntrico em direção a conceitos e teorias nacionais. Esses discursos dos estudos da tradução tomam emprestados dois códigos linguísticos (a língua romena versus uma língua amplamente falada - principalmente inglês, francês, alemão, mas também espanhol ou italiano), mas nem sempre se dirigem a um público com um horizonte de expectativa específico para o código escolhido, particularmente se os estudos da tradução nas línguas estrangeiras referemse a pesquisas realizadas nessa e por essa área.

Se quisermos falar de um futuro dos estudos da tradução em geral e dos estudos da tradução nacionais em particular, consideramos necessário reduzir o abismo entre o pequeno número de estudos da tradução publicados nas línguas nacionais, que importam modelos, métodos e os adaptam à especificidade da língua materna do autor, e o número excessivo de publicações em línguas como o inglês, o francês ou o alemão. Definir o perfil dos leitores dos estudos da tradução e situá-los num eixo linguístico e histórico poria fim à paralisia da pesquisa em termos de recepção e ajudaria a abrir o horizonte de tradução de todos os atores envolvidos de uma forma ou de outra na produção, publicação e distribuição de traduções, bem como na formação de tradutores. 


\section{REFERENCIAS}

BALLIU, Christian. Clefs pour une histoire de la traductologie soviétique. Meta, v. 50, n. 3, p. 934-948, 2005.

CANDEA, Virgil. Nicolae Milescu şi începuturile traducerii umaniste în limba română [Nicolae Milescu and the beginnings of humanist translation into Romanian]. Limbă și Literatură 7, p. 29-76, 1963.

COSTANTINO, Lorenzo (ed.). Teorie della traduzione in Polonia. Settecittà: Viterbo, 2009.

FEDOROV, Andrei V. Vvedenie v teoriju perevoda. [Introduction to the theory of translation]. Moscow: Literatura na inostr. Introducere în teoria traducerii. [Anonymous translation into Romanian]. Bucuresti, 1953.

FRIEDBERG, Maurice. Literary Translation in Russia. A Cultural History. University Park, Pennsylvania: The Pennsylvania State Univ. Press, 1997.

GHIȚA, Elena. Qu'est-ce que la traductologie?. Buletinul ştiinţific al Facultăţii de învăţământ pedagogic. Piteşti, p. 443-447, 1980.

GHIȚĂ, Elena. Pentru o definiţie a traductemului (I) [Towards a Definition of the Translation Unit]. Analele Universităţii din Timişoara, Seria Ştiinţe Filologice, v. 20, p. 63-72, 1982.

GHIȚĂ, Elena. Pentru o definiţie a traductemului (II) [Towards a Definition of the Translation Unit], Analele Universităţii din Timişoara, Seria Ştiinţe Filologice, v. 21, p. 6167, 1983.

GHIȚA, Elena. Le statut actuel de la traductologie. In : ŢENCHEA, M. (éd.). Études de traductologie. Timişoara: Mirton, 1999. p. 5-15.

GREBENSCHIKOV, Vladimir. Traductions, théories et traducteurs en U.R.S.S. Meta 1, p. 38, 1967.

IORGA, Nicolae. Traducerile din limba franceză în literatura românească [Translations from French into Romanian Literature]. Vălenii de munte: Tipografia Datina românească, 1936.

JACQUIER, Henri. Babel mit viu [Babel, a Living Myth]. Edited, selected, foreword, notes, and comments by Mircea Muthu. Cluj-Napoca: Dacia, 1991.

KITTEL, Harald; FRANK, Armin Paul; GREINER, Norbert; HERMANS, Theo; KOLLER, Werner; LAMBERT, Josè; PAUL, Fritz (ed.). Übersetzung, Translation, Traduction. Ein internationals Handbuch zur Übersetzungsforschung. Berlin/New York: De Gruyter, 2004.

KOGĂLNICEANU, Mihail. Moldau und Wallachei. Romänische oder wallachische Sprache und Literatur. Von einem Moldauer. Magazin für die Literatur des Auslandes, 8, p. 29-30, 1837. 
KOGĂLNICEANU, Mihail. Introducţie [Introduction], in „Dacia literară”. In:

KOGĂLNICEANU, Despre literatură [About Literature]. Bucureşti: Editura de Stat pentru Literatură şi Artă, p. 53-58, 1956 [1840].

KOHN, Ioan. Virtuţile compensatorii ale limbii române în traducere [Compensating features of Romanian in translation]. Timişoara: Facla, 1983.

KOMISSAROV, Vilen N. La traduzione nella cultura russa. In: ULRYCH, M. (ed). Tradurre: un approccio multidisciplinare. Torino: Utet, 2003. p. 317-332.

LOGHIVOVSKI, Elena. Eminescu în limba lui Puşkin [Eminescu in Pushkin's Language]. Iaşi: Junimea, 1989.

LUNGU-BADEA, Georgiana (dir.) Etudes de traductologie romaine I. Discours traductif, discours métatraductif. Timişoara: Editura Universităţii de Vest, 2017a.

LUNGU-BADEA, Georgiana (dir.) Etudes de traductologie romaine II. Essai de cartographier la recherche roumaine. Timişoara: Editura Universității de Vest, 2017b.

LUNGU-BADEA, Georgiana. Idei și metaidei traductive românești (sec. XVI-XXI) [Ideas and Metaideas of Romanian Translation (from the 16th Century to the 21st Century)]. Timişoara: Editura Universității de Vest, 2015 [2013].

LUNGU-BADEA, Georgiana. Tendinţe în cercetarea traductologică [Tendencies in translation studies research]. Direction: Georgiana Lungu-Badea et Alina Pelea. Timişoara: Editura Universității de Vest, 2005.

LUNGU-BADEA, Georgiana; PELEA, Alina. Enseigner et apprendre à traduire de "façon raisonnée”. Timişoara: Editura Universității de Vest, 2015.

LUPAN, Radu. Translators and translation in Romania. The incorporated linguist, v. 2, n. 34, 1968.

MAIORESCU, Titu. Limba română în jurnalele din Austria [The Romanian Language in the Press from Austria]. In: MAIORESCU, Titu, Critice. Bucureşti: Editura pentru Literatură, 1966 [1868]. p. 13-46.

MAIORESCU, Titu. Beţia de cuvinte. Revista contimporană (Studiu de patologie literată) [Word Intoxication in "The Contemporary Review" (A Study in Literary Pathology)]. In: MAIORESCU, Titu. Critice. Bucureşti: Editura pentru Literatură, 1966 [1873]. p. 147-163.

MAIORESCU, Titu ([1881]/1966): "În contra neologismelor" [Against Neologisms]. In: MAIORESCU, Titu. Critice. Bucureşti: Editura pentru Literatură, 1966. p. 331-352.

MAIORESCU, Titu. Critice [Critical Works]. Selections and foreword by Paul Georgescu, text edited Domnica Stoicescu. Bucureşti: Editura pentru Literatură, 1966. 
MARCUS, Solomon. Cum depinde un text de limba în care a fost scris (Interpretându-l pe Sorescu) [How does a text depend on the language in which it was written (Interpreting Sorescu)]. Studii şi cercetări lingvistice, v. 35, n. 4, p. 288-296, 1984.

MAVRODIN, Irina. Traducerea o practico-teorie [Translation as a Practical Theory]. In: MAVRODIN, Irina. Modernii-precursori ai clasicilor [The Moderns: Precursors of the Classics]. Cluj-Napoca: Dacia, p. 191-209, 1981.

MICLĂU, Paul. Signes poétiques. Bucureşti: Editura Didactică şi Pedagogică, 1983.

MIKO, Frantiśek. La Théorie de l'expression et la traduction. In: HOLMES J. S. (ed.): The Nature of Translation. The Hague: Mouton, 1970. p. 61-77.

MOUSSAKOVA, Svetla. Le Miroir identitaire. Histoire de la construction culturelle de l'Europe. Transferts et politiques culturels en Bulgarie. Paris: Presses Sorbonne Nouvelle, 2007.

MUNTEANU, Eugen. Studii de lexicologie biblică [Studies of Biblical lexicology]. Iaşi: Editura Universităţii, 1995.

OSIMO, Bruno. The Fundamentals of Translation. Introductory course with exemplifying tables. [Translated from Italian by Alice Rampinelli, Anna Paradiso \& Bruno Osimo.].

126 Disponível em: http://www.trad.it/the-fundamentals-of-translation-ebookby-bruno-osimo/. ISBN 9788898467099. 2014.

OSIMO, Bruno. Aleksandr Ludskanov, un approccio semiotico ala traduzione. In :

CARMIGNANI, Ilide; ARDUINI, Stefano (ed.). Quaderni del centro per il libro e la lettura. Roma: Centro per il libro e la lettura, 2010. p. 201-216.

OSIMO, Bruno (ed.). Manuale del traduttore. Milan: Hoepli, 2004.

PICCHIANTI, Massimo; JAMPOL'SKAJA, Anna. Sulla teoria della traduzione in Russia. Studi Italiani di Linguistica Teorica e Applicata 1, p. 59-76, 1995.

POPOVIČ, Anton. La scienza della traduzione. Aspetti metodologici. La comunicazione traduttiva. [Traduzido por Bruno Osimo e Daniela Laudani]. Milano: Hoepli, 2006.

RECKER, Iakov; GREBENSCHIKOV, Vladimir . Les objectifs de l'analyse comparée des traductions. Journal des traducteurs, v. 9, n. 3, p. 75-83, 1964.

SCHIPPEL, Larisa. Die Übersetzungskultur in Rumänien. In: KITTEL, H.; FRANK, A.P.; GREINER, N.; HERMANS, T.; KOLLER, W.; LAMBERT, J.; PAUL, F. (ed.). Übersetzung. Translation. Traduction. Ein internationales Handbuch zur Übersetzungsforschung. Berlin; Boston: de Gryuter, 2012. p. 2114-2123.

ŠVEJCER, Alexander D. Linguistics and Translation: a Changing Relationship. Voprosy filologii, v. 1, n. 4, p. 59-65, 2000. 
TABAKOWSKA, Elzbieta. Cognitive Linguistics and Poetics of Translation. Tübingen: Gunter Narr, 1993.

ȚENCHEA, Maria (éd.). Études de traductologie. Timişoara: Mirton, 1999.

URSU, Neculai Alexandru. Cine este Gherasim, traducătorul lui Voltaire (1792)? [Who Is Gherasim, Voltaire's Translator]. Cronica 21, v. 1, n. 4, 1986.

WANDRUSKA, Mario. Die Mehrssprachigkeit des Menschen. München: Piper \& Co, 1979.

ZLATEVA, Palma (ed.). Translation as Social Action. Russian and Bulgarian Perspectives. London/New York: Routledge, 1993.

\footnotetext{
* Georgiana LUNGU-BADEA - Doutora (2003) e Mestre (1992) em Literatura Francesa pela Université de l'Ouest de Timisoara. Professora titular da Universidade do Oeste de Timisoara, diretora da École doctorales en Sciences Humaines et Sociales (Faculté des Lettres, Histoire et Théologie) e professora visitante do Programa de PósGraduação em Estudos da Tradução (POSTRAD) da Universidade de Brasília. Université de l'Ouest de Timisoara, Faculté des Lettres, Histoire et Théologie, Département de langues. Universidade de Brasília, Programa de PósGraduação em Estudos da Tradução (POSTRAD) da Universidade de Brasília. Timisoara, Romênia. Brasília, Distrito Federal, Brasil.

Currículo acadêmico: https://litere.uvt.ro/wp-content/uploads/2014/07/03.CV_Georgiana_Lungu_Badea.pdf ORCID: https://orcid.org/0000-0002-0786-0412
}

E-mail: georgiana.lungu-badea@e-uvt.ro

** A tradução do artigo abaixo referenciado e sua publicação foram autorizadas pela autora, Georgiana LunguBadea e pela editora Frank\&Timme.

LUNGU-BADEA, Georgiana. Translation studies in Romania. Their synchronic and deferred relations with European translation studies. A few directions of research. In: SCHIPEL, Larisa; ZWISCHENBERGER, Cornelia (ed.). Going East: Discovering New and Alternative Traditions in Translation Studies. Berlin: Frank\&Timme, 2016. p. 47-76.

*** Ana Alethea de Melo Cesar OSÓRIO - Bacharel em Letras - Tradução/Inglês (2011) pela Universidade de Brasília. Especialista em Revisão de Textos (2015) pelo Centro Universitário de Brasília. Mestre em Estudos da Tradução (2020) na Universidade de Brasília. Revisora de textos na Editora Universidade de Brasília. Universidade de Brasília, Instituto de Letras, Programa de Pós-Graduação em Estudos da Tradução. Brasília, Distrito Federal, Brasil.

Currículo acadêmico: http://lattes.cnpq.br/5685363692393264

ORCID: https://orcid.org/0000-0002-2101-9566

E-mail: anaalethea@gmail.com

${ }^{1}$ A pesquisa sobre este tópico, que teve origem em Tendinţe în cercetarea traductologică [Tendências de pesquisa nos estudos da tradução], 2005, estendeu-se para abarcar também a perspectiva histórica (Scurtă istorie a traducerii. Repere traductologice [Breve história da tradução. Pontos de referência nos estudos da tradução], 2007) e tentar formular uma resposta para a pergunta "Existe pesquisa em tradução na Romênia?" em Idei şi metaidei traductive românești (sec. XVI-XXI) [Ideias tradutológicas e metatradutológicas romenas: séculos XVI a XX], [2013]/2015). A terminologia e a metalinguagem dos estudos da tradução foram abordados em Mic dicţionar de termeni utilizaţi în teoria, practica şi didactica traducerii [Dicionário de termos utilizados na teoria, prática e didática da tradução], que teve três edições: 2003, 2008, 2012.

${ }^{2}$ A fim de traçar algumas direções para o desenvolvimento de estudos gerais de tradução, para além das fronteiras geográficas, a pesquisa realizada por uma equipe internacional pode ser útil no que diz respeito aos estudos da tradução na Bulgária, Croácia, Moldávia, Romênia, Sérvia, Eslovênia, Hungria, etc.

${ }^{3}$ HARRIS, B., La traductologie, la traduction naturelle, la traduction automatique et la sémantique, 1973; e What I Really Meant by Translatology, 1988. 
${ }^{4}$ LADMIRAL, J.-R. (ed.), La Traduction, Langages, n. 28, dez. 1972.

${ }^{5}$ WILSS, W., Übersetzungswissenschaft. Probleme und Methoden, 1977, e Translation and Interpreting in the 20th Century: focus on German, 1999.

${ }^{6}$ Slavesky, Heidemarie (Hrsg.), Sachwörterbuch des Translationswissenschaft, Berlin, Julius Groos Verlag.

${ }^{7}$ Apenas mencionaremos as linhas fundamentais: 1) foco no propósito da tradução (REISS, Möglichkeiten und Grenzen der Übersetzungskritik. München: Hueber, 1971, REISS; VERMEER, Grundlegung einer allgemeinen Translationstheorie. Tübingen: Niemeyer, 1984), ver também o funcionalismo de Nord (1993); 2) a ação e mudança de paradigma (HOLZ-MÄNTTARI, Translatorisches Handeln, Helsinki, Suomalainen Tiedeakatemia, 1984, "Das Transfer-Prinzip", In: R. ARNT; G. THOME, eds. Übersetzungswissenschaft. Ergebnisse und Perspektiven. Tübingen: Narr, 1990, 59-70), tradução construtiva (HÖNIG, Konstruktives Übersetzen. Tübingen: Stauffenburg. 1995); e 3) a tentativa de transferência cultural, predominante nos anos 1970 e 1980 (VERMEER, Kulturspezifik des translatorischen Handelns. Heidelberg: Universität Heidelberg, 1990; KOLLER, Einführung in die Übersetzungswissenschaft, Heidelberg, 1992), e a cultura em si, além do espírito do culturalismo na tradução (BASNETT; LEFEVERE (eds.), Translation, History and Culture. London/New York: Pinte 990).

8 Чуковский К. Принципы художественного перевода : статьи / К. Чуковский, Н. Гумилев. - Пб.: Изд-во «Всемирная литература», 1919. - 31 c. CIUKOVSKI, K, GUMILIOV, N., Principy chudožestvennogo perevoda: stat'i, Izd-Vo „Vsemirnaja literatura”, 1919, 31c.

9 TOURY, Interlanguage and its Manifestations in Translation, 1979, In: Search of a Theory of Translation, 1980, Translation Across Cultures, 1987, e, com Even-Zohar, Translation Theory and Intercultural Relations, 1981, Even-Zohar com Polysystem Theory, 1979, e Polysystem Studies, 1990.

${ }^{10}$ Coşeriu, fundador da linguística integral, internacionalmente conhecido por sua teoria das mudanças linguísticas, seus estudos sobre alteridade e universalidade linguística; suas obras, no entanto, ainda não foram todas traduzidas para o romeno.

${ }^{11}$ Coşeriu, Lo erróneo y lo acertado en la teoría de la traducción [1976], In: Coşeriu, El hombre y su lenguaje,

128 Madrid, Gredos, 1991, p.214-239.

$13 \mathrm{O}$ autor búlgaro só menciona outros dois autores búlgaros: A. Ljudskanov, "The principle of functional equivalence", In: The art of translation, Sofia, ed. Narodna Cultura, 1969, p. 99-115; e I. Nikolova, Dynamic texts: Issues of translation and adaptation, Sofia, ed. Petko Venedikov, 2005.

${ }^{14}$ Gutu acrescenta uma coletânea de artigos científicos chamada Unele probleme de teorie, empirism şi didactică a limbilor [Alguns aspectos de teoria da linguagem, empirismo e didática] (2005), publicado em Quisinau, mas em romeno. Uma abordagem similar, mas no sentido contrário, aparece em nossos trabalhos e artigos: romeno para os livros e francês para os artigos.

${ }^{15}$ Ver também English with a Key (1996, 1999), em que L. Vianu examina a tradução como método de aprendizagem de inglês.

${ }^{16}$ JAKOBSON, On Linguistic Aspects of Translation (1959); MOUNIN, Les Problèmes théoriques de la traduction (1963, 1972); NIDA, Toward a Science of Translation (1964); CATFORD, A Linguistic Theory of Translation (1965); CHARAUDEAU, Problématique linguistique de la traduction (1972); PERGNIER, Traduction et théorie linguistique (1972); DYRUL, Problèmes de l'aspect linguistique de la traduction, SCHMITT, Traduction et linguistique, REISS ; VERMEER, Grundlegung einer Translationstheorie (1984); GARNIER, Linguistique et traduction (1985), CHUQUET ; PAILLARD, Approche linguistique des problèmes de la traduction (1987); MALONE, The Science of Linguistics in the Art of Translation, 1988; BAKER, In Other Words: A Coursebook on Translation (1992); CHEVALIER ; DELPORT, L'Horlogerie de Saint Jérôme, problèmes linguistiques de la traduction (1995), VENUTI, The Translation Studies Reader (2012), etc.

${ }^{17}$ In: Legendele Troadei în literatura veche românească [Lendas da Trôade na literatura romena antiga], Bucureşti, 1925, Academia Rom. Memoriile secţiunii literare, seria III, tomul III, mem.3.

${ }^{18}$ Abordamos esse assunto em Übersetzungsmethoden im Rumänischen im 18. und 19. Jahrhundert. Politische, sprachliche, ethische und ästhetische Problemstellungen. In: JEANRENAUD, RICHTER, SCHIPPEL (eds.): "Traducerile au de cuget să îmblînzească obiceiurile”. Rumänische Übersetzungsgeschichte - Prozesse. Produkte. Akteure, Frank e Timme, Berlin 2014, p. 33-60, e amplamente em Idei şi metaidei traductive româneşti (sec. XVI-XXI). Timişoara, Editura Eurostampa, 2013.

${ }^{19}$ COȘERIU, Stiernhielm, limba română şi ciudatul destin al unui Tatăl nostru. Un capitol din istoria cunoaşterii (şi necunoaşterii) românei în Europa occidentală [Stiernhielm, a língua romena e o estranho destino de uma versão do Pai Nosso. Um capítulo na história do conhecimento (e desconhecimento) sobre a Romênia na Europa Ocidental] (1994, p. 45-63).

${ }^{20}$ LODGE, Limbajul romanului (The Language of Fiction). Tradução de R. Paraschivescu. Bucareste, Univers, 1998, p.12-13.

${ }^{21}$ MOUNIN, "Intraduisibilité comme notion statistique", In: Babel, 3, 1964, p. 122 apud KOHN, 1979, p. 50. 
${ }^{22}$ Existe uma relação explícita com os dois tipos de intraduzibilidade (linguística e cultural) e de tradução (restrita e total) teorizados por Catford (1965, p. 22, 27, 101).

${ }^{23}$ Ghiță, em Equivalences roumaines de la poésie symboliste française [Equivalências romenas da poesia simbolista francesa], 1978, faz um estudo comparativo das versões romenas dos poemas simbolistas franceses, com foco no resultado da tradução, e implicitamente nos métodos de tradução, e na análise de sua influência no nível do texto. Stanciu foca sua tese Teoria traducerii aplicată la studiul comparativ al limbilor germană şi română [Teoria da tradução aplicada ao estudo comparativo do alemão e do romeno], 1978, no estudo sistemático do alemão e do romeno na relação de tradução. A análise de microestruturas complexas, na perspectiva da entropia informacional e estilística, parte da transferência de arcaísmos e regionalismos. Ao contrário da tese mencionada anteriormente, na tese de doutorado chamada Teoria compensaţiei în stilistica traducerii [Teoria da compensação na estilística comparada], (1979), Kohn investiga os problemas estéticos e estilísticos da tradução, os recursos ocultos da palavra e a possibilidade de enriquecer um texto-fonte por meio de uma tradução bem feita.

${ }^{24}$ IVANOVICI, Un caftan pentru Don Quijote, p. 7-125.

${ }^{25}$ Idem, ibidem, p. 51 et seq.

26 A primeira edição foi publicada em 1979 (Paris, Payot). A edição consultada para este trabalho foi uma reimpressão da Gallimard. [Há uma tradução portuguesa publicada no mesmo ano pela Europa-América: LADMIRAL, J-R. Traduzir: teoremas para a tradução. Tradução de Geminiano Cascais Franco. Lisboa: EuropaAmérica, 1979. (Biblioteca universitária)]

${ }^{27}$ IVANOVICI, p. 150 e seguintes.

${ }^{28}$ LUNGU-BADEA, Mic dicţionar de termeni utilizaţi în teoria, practica şi didactica traducerii [Dicionário de termos empregados na teoria, prática e didática da tradução], Timisoara, Editura Universitatii de Vest [2003], 2012.

${ }^{29}$ Vocabularul românesc contemporan. Schiţă de system [O vocabulário romeno contemporâneo: esboço de um sistema], Timişoara, Editura Facla, 1978.

${ }^{30}$ M. CONSTANTINESCU, Lire et traduire la litterature de jeunesse [Ler e traduzir a literatura juvenil], Editura Universităţii "Ştefan cel Mare", 2009.

${ }^{31}$ C. Dascălu, por exemplo, ocupou-se com a tradução poética em Dificultăţi şi performanţe în traducerea de poezie [Dificuldades e êxitos na tradução de poesia], 2012.

32 A transferência interligual de substantivos próprios é motivo de reflexão (Translationes, 3/2011), para a tradução (BALLARD, Le Nom propre en traduction, Numele proprii în traducere [O nome próprio na tradução], Timişoara, Editura Universităţii de Vest, 2011); particularidades da autotradução, da linguagem religiosa, etc.

${ }^{33}$ L. VLEJA, "Sobre los comienzos de las traducciones del español al rumano", 2007; M. ŢĂRAN ANDREICI, Introducere în teoria şi practica traducerii, aplicată la studiul comparativ al limbilor sârbă şi română [Introdução à teoria e à prática da tradução aplicadas ao estudo comparado do sérvio e do romeno], Timişoara, Editura de Vest, 2014.

${ }^{34}$ Ver Repertórios de traduções e tradutores, estudos da história da tradução romena, reunidos pelo grupo de pesquisa ISTTRAROM-Translationes, Universidade do Oeste de Timisoara.

${ }^{35}$ Esse projeto é patrocinado pela INALCO-Paris e coordenado por M. Vrinat Nikolaev. O objetivo primordial do CEEM (Centre d'études de l'Europe médiane) é estudar 18 culturas europeias: bósnia, búlgara, checa, croata, estoniana, grega, letã, lituana, macedônica, húngara, montenegrina, polonesa, romena, sérvia, eslovaca, eslovena, $\begin{array}{llll}\text { sorábia } & \text { e } & \text { (Disponível em: }\end{array}$ http://histrad.info/index.php?option=com_content\&view=category\&layout=blog\&id=54\&Itemid=85)

${ }^{36}$ Ver também: M. Baker (ed.), Routledge Encyclopedia of Translation Studies, (2001); Mary Snell-Hornby, The Turns of Translation Studies: New Paradigms or Shifting Viewpoints? (2006).

${ }^{37}$ Bruxelas, De Boeck Superieur, coleção “Traducto”, 2013 (234 p), p. 150-152.

38 É uma desaprovação reversa como fizeram Nadja Grbić e Michaela Wolf, La traductologie dans les pays germanophones: état actuel (TTR: traduction, terminologie, rédaction, v. 9, n. 1, 1996, p. 279-299. Disponível em: http://id.erudit.org/iderudit/037248ar) aos estudos da tradução publicados em alemão, com um egocentrismo traído pela impermeabilidade à pesquisa não germânica (1996, p. 296). 